\title{
Acúmulo de matéria seca e macronutrientes por cultivares de sorgo sacarino
}

\section{Accumulation of dry matter and macronutrients in sweet sorghum cultivars}

\author{
Edimar Rodrigues Soares ${ }^{1 *}$; Edson Luiz Mendes Coutinho ${ }^{2}$; \\ Sérgio Bispo Ramos ${ }^{3}$; Márcio Silveira da Silva ${ }^{1}$; José Carlos Barbosa ${ }^{4}$
}

\section{Resumo}

As curvas de acúmulo de nutrientes auxiliam na compreensão das demandas nutricionais de uma cultura. O objetivo deste trabalho foi avaliar o crescimento e o acúmulo de macronutrientes pelos híbridos de sorgo sacarino CVSW80007, CVSW80147, CVSW82028, CVSW82158. O experimento foi conduzido em uma área de renovação de cana-de-açúcar no município de Uchoa-SP, sendo implantado em janeiro de 2012. As plantas foram coletadas em intervalos de 15 dias a partir do décimo dia após a emergência (DAE). O maior acúmulo de matéria seca, N, P, Mg e S, foi obtido pela cultivar CVSW82028, enquanto a 'CVSW82158' extraiu a maior quantidade de K e a 'CVSW80147,' de Ca. Os colmos representaram o maior percentual de matéria seca e nutrientes acumulados, com exceção do nitrogênio e do fósforo, em que os grãos corresponderam a maior porcentagem do total absorvido. As cultivares CVSW80007, CVSW82028 e CVSW82158 apresentaram a seguinte ordem decrescente de extração de nutrientes: $\mathrm{N}>\mathrm{K}>\mathrm{Ca}>\mathrm{Mg}>\mathrm{P}>\mathrm{S}$ e a 'CVSW80147', $\mathrm{K}>\mathrm{N}>\mathrm{Ca}>\mathrm{Mg}>\mathrm{P}>\mathrm{S}$. Considerando apenas colmo, a ordem decrescente de exportação de nutrientes é a mesma para todas as cultivares: $\mathrm{K}>\mathrm{N}>\mathrm{Ca}>\mathrm{Mg}>\mathrm{S}>\mathrm{P}$. No entanto, a sequência decrescente de exportação de nutrientes considerando colmos e grãos, é para as cultivares CVSW80007, CVSW80147 e CVSW82158: $\mathrm{K}>\mathrm{N}>\mathrm{Ca}>\mathrm{Mg}>\mathrm{P}>\mathrm{S}$ e $\mathrm{K}>\mathrm{N}>\mathrm{Mg}>\mathrm{Ca}>\mathrm{P}>\mathrm{S}$ para a 'CVSW82028'.

Palavras-chave: Biocombustível, Sorghum bicolor (L.) Moench, marcha de absorção

\begin{abstract}
Nutrient accumulation curves help us understand the nutritional demands of a crop. The aim of this study was to evaluate the growth and accumulation of macronutrients by the sweet sorghum cultivars CVSW80007, CVSW80147, CVSW82028, CVSW82158. The experiment was conducted in a renewal sugarcane ratoon area at Uchoa county, SP, being deployed in January 2012. The plants were collected in 15 days intervals from the $10^{\text {th }}$ after emergence (DAE). The greatest content of dry matter, $\mathrm{N}, \mathrm{P}, \mathrm{Mg}$ and S, was due to by the CVSW82028 cultivar, while the CVSW82158 extract the greatest amount of $\mathrm{K}$ and the CVSW80147 of Ca. The stalks represented the highs percentage of dry matter and nutrient content, except nitrogen and phosphorus, in which grains corresponded to the higher percentage of total absorption. The CVSW80007, CVSW82028 and CVSW82158 cultivars showed the following decreasing nutrient extraction $\mathrm{N}>\mathrm{K}>\mathrm{Ca}>\mathrm{Mg}>\mathrm{P}>\mathrm{S}$ and the CVSW80147, $\mathrm{K}>\mathrm{N}>\mathrm{Ca}>\mathrm{Mg}>\mathrm{P}>\mathrm{S}$. Considering only
\end{abstract}

\footnotetext{
${ }^{1}$ Discentes do Curso de Doutorado do Programa de Pós-Graduação em Agronomia, Ciência do Solo, Universidade Estadual Paulista, Faculdade de Ciências Agrárias e Veterinárias, UNESP/FCAV, Campus de Jaboticabal, SP. Bolsista da CAPES. E-mail: soares-agro@hotmail.com; marciode@hotmail.com

2 Prof. Titular, do Dept ${ }^{\circ}$ de Solos e Adubos, UNESP/FCAV, Campus de Jaboticabal, SP. E-mail: coutinho@fcav.unesp.br

3 Prof. Dr., Faculdade Metropolitana de Anápolis, FAMA, Anápolis, GO. E-mail: bispo.ramos@bol.com.br

${ }^{4}$ Prof. Titular, Dept ${ }^{\circ}$ de Ciências Exatas, UNESP/FCAV, Campus de Jaboticabal, SP. E-mail: jcbarbosa@fcav.unesp.br

* Autor para correspondência
} 
the stalks harvest, the decreasing nutrient exportation is the same for all cultivars: $\mathrm{K}>\mathrm{N}>\mathrm{Ca}>\mathrm{Mg}>\mathrm{S}>\mathrm{P}$. Whereas the decreasing nutrient exportation sequence considering stalks and grain harvest is the following for the CVSW80007, CVSW80147 and CVSW82158 cultivars: $\mathrm{K}>\mathrm{N}>\mathrm{Ca}>\mathrm{Mg}>\mathrm{P}>\mathrm{S}$ and $\mathrm{K}>\mathrm{N}>\mathrm{Ca}>\mathrm{Mg}>\mathrm{P}>\mathrm{S}$ for the CVSW82028.

Key words: Biofuel, Sorghum bicolor (L.) Moench, absorption rate

\section{Introdução}

A limitação das reservas mundiais de petróleo e a instabilidade no mercado deste produto, tem estimulado em todo mundo, a busca por matériasprimas com potencial de uso para produção de energia. Nesse sentido, a utilização de energia renovável a partir da biomassa vegetal é uma alternativa viável, sendo que o Brasil destaca-se, nesse quesito, como grande produtor de etanol a partir da cana-de-açúcar (MAPA, 2006).

O Brasil é responsável por 20 e $50 \%$ das exportações mundiais de etanol e açúcar, respectivamente. Em relação ao açúcar, para suprir a demanda interna e continuar a manter esse percentual de exportação, a produção brasileira terá que aumentar 15 milhões de toneladas até 2020 (UNICA, 2012). Vale ressaltar que isto significa um aumento de $44 \%$ em relação à produção atual.

Embora a cana-de-açúcar provavelmente continuará a ser principal matéria-prima utilizada para a produção de etanol, outras culturas podem ser utilizadas para a produção deste biocombustível (MAPA, 2006). O sorgo sacarino (Sorghum bicolor (L.) Moench) tem sido sugerido por diversos autores como matéria-prima potencial para a produção de etanol, por apresentar alta capacidade de produção de biomassa, e armazenar no colmo açúcares fermentáveis que podem ser convertidos em combustível liquido (ERICKSON et al., 2011; ROONEY et al., 2007; VENTURI; VENTURI, 2003; WU et al., 2010; ZHAO et al., 2009). Estudos recentes indicam que essa poaceae apresenta excelente potencial para uso em áreas de renovação de cana-de-açúcar que representam aproximadamente 1,3 milhões de ha ou $16 \%$ da área existente (KLINK, 2010).
De acordo com Parrella et al. (2010) o sorgo sacarino pode servir como matéria prima complementar na entressafra da cana, antecipando em 2 a 3 meses o período de moagem nas usinas e podendo reduzir a oscilação no preço do etanol nesse período.

Salienta-se que há na literatura poucas informações sobre a demanda nutricional da cultura do sorgo sacarino, ao mesmo tempo que, os dados existentes são de experimentos antigos (ROSOLEM; MALAVOLTA, 1981a) e conduzidos com variedades, contrastando com o cenário atual, com tendência ao uso de híbridos. Teoricamente, esses materiais são mais uniformes, apresentam maior produtividade e exigência nutricional.

Assim sendo, o estudo do acúmulo de nutrientes em função da idade das plantas é de fundamental importância para auxiliar na definição das quantidades e épocas de aplicações de fertilizantes, contribuindo para o aumento da eficiência no manejo da cultura proporcionando ganhos em produtividade e na redução dos custos de produção, através da utilização racional e eficiente dos insumos.

Neste contexto, objetivou-se com esse trabalho determinar em função do tempo o acúmulo de matéria seca e macronutrientes em cultivares de sorgo sacarino.

\section{Material e Métodos}

O experimento foi conduzido no município de Uchoa-SP, em uma área de renovação de cana-deaçúcar, localizado a uma latitude 20 $53^{\circ}$ '42"S e a uma longitude $49^{\circ} 11^{\prime} 21^{\prime \prime} \mathrm{O}$, altitude de $552 \mathrm{~m}$. O solo do local foi classificado, utilizando-se os critérios de EMBRAPA (2006), como Latossolo VermelhoAmarelo distrófico, textura média. Os atributos do 
solo na camada arável $(0-20 \mathrm{~cm})$ foram: $\mathrm{pH}\left(\mathrm{CaCl}_{2}\right)$ 5,6; M.O. $=9 \mathrm{mg} \mathrm{dm}{ }^{-3}$; P (resina) $=44 \mathrm{mg} \mathrm{dm}^{-3}$; $\mathrm{K}, \mathrm{Ca}, \mathrm{Mg}, \mathrm{H}+\mathrm{Al}$, e $\mathrm{CTC}=1,6 ; 29 ; 11 ; 15 ; 56,6$ mmol $\mathrm{dm}^{-3}$, respectivamente; $\mathrm{S}^{-\mathrm{SO}_{4}}=2 \mathrm{mg} \mathrm{dm}^{-3}$; saturação por bases $(\mathrm{V} \%)=73 ; \mathrm{B}$ (água quente), $\mathrm{Cu}, \mathrm{Fe}, \mathrm{Mn}$ e $\mathrm{Zn}(\mathrm{DTPA})=0,15 ; 2.0 ; 18 ; 14,0$ e 0,8 $\mathrm{mg} \mathrm{dm}{ }^{-3}$, respectivamente (RAIJ et al., 2001). Em termos de análise granulométrica, o solo apresenta textura média com teor de argila, silte e areia de 174; 1 e $825 \mathrm{~g} \mathrm{~kg}^{-1}$, respectivamente, determinados de acordo com os métodos propostos por Camargo et al. (2009).

Os híbridos de sorgo sacarino utilizados foram: CVSW80007, CVSW80147, CVSW82028 e CVSW82158, sendo que estes foram semeados em 22 de janeiro de 2012, com espaçamento de $0,70 \mathrm{~m}$ entre linhas. Na adubação de plantio foram aplicados 20, 60 e $60 \mathrm{~kg} \mathrm{ha}^{-1}$, respectivamente de $\mathrm{N}, \mathrm{P}_{2} \mathrm{O}_{5}$ e $\mathrm{K}_{2} \mathrm{O}$. A emergência das plantas ocorreu aos 7 dias após a semeadura. Em cobertura, aos 20 dias após a emergência (DAE) das plantas (estádio V4) foram aplicados $40 \mathrm{~kg} \mathrm{ha}^{-1}$ de $\mathrm{K}_{2} \mathrm{O}$ e $100 \mathrm{~kg} \mathrm{ha}^{-1}$ de $\mathrm{N}$ na forma de cloreto de potássio e ureia, respectivamente. O desbaste foi realizado aos 15 DAE, deixando um total de 8 plantas por metro linear, como intuito de se obter um estande de 120.000 plantas ha-1. Após o desbaste realizouse a aplicação do herbicida Atrazina (2 kg i.a. ha-1), visando o controle de plantas daninhas.

As plantas foram cortadas rente ao solo, sendo as amostragens realizadas em intervalos de 15 dias a partir do décimo DAE, até os 100 DAE. Na primeira coleta, foram amostradas 15 plantas e nas demais, cinco plantas. No laboratório, as plantas foram separadas em colmo, folha, panícula e grãos, quando presentes. As partes das plantas foram lavadas em água com detergente, passadas em água corrente, imersão em solução com $0,1 \mathrm{~mol} \mathrm{~L}^{-1} \mathrm{HCl}$ e em seguida em água destilada. Após a lavagem foram acondicionadas em sacos de papel e secas em estufa de circulação forçada de ar a $65^{\circ} \mathrm{C}$, até atingir massa constante. Logo após, pesou-se as amostras para a obtenção da produção de matéria seca, em seguida moídas em moinho tipo "Wiley" e guardadas em sacos de papel até a realização das análises químicas. As análises químicas foram realizadas em triplicata, sendo que a determinação das concentrações de $\mathrm{N}, \mathrm{P}, \mathrm{K}, \mathrm{Ca}, \mathrm{Mg}, \mathrm{S}$, foram realizadas de acordo com os métodos descritos por Bataglia et al. (1983).

$\mathrm{O}$ acúmulo de nutrientes em cada parte da planta foi calculado por meio da relação entre a concentração de cada nutriente nas mesmas pela matéria seca (MS) de cada parte (concentração do nutriente na parte x MS (g) / 1000) e, em seguida, transformados em $\mathrm{kg}$ por hectare.

O ajuste para os acúmulos de matéria seca e macronutrientes em função do tempo foram realizados por meio de modelos de regressão. Utilizou-se o programa Sigmaplot ${ }^{\circledR} 10.0$, adotandose a equação com maior coeficiente de determinação $\left(\mathrm{R}^{2}\right)$ que melhor representasse o fenômeno. Como houve padrões de acúmulo distintos, foi necessário a utilização de quatro modelos, sendo estes:

1) logístico com três parâmetros:

$$
\mathbf{Y}=\frac{\mathbf{a}}{1+e^{-\frac{\left(\mathrm{x}-\mathrm{x}_{0}\right)}{\mathbf{b}}}}
$$

Sendo, $\mathrm{a}=$ máximo assintótico; $\mathrm{b}=$ taxa de crescimento e $\mathrm{x}_{0}=$ ponto de inflexão. Através desta, calculou-se as curvaturas mínima $\left(\mathrm{C}_{\min }\right)$ e máxima $\left(\mathrm{C}_{\max }\right)$ conforme o método citado por Venegas; Harris e Simon (1998), utilizando os parâmetros das equações não lineares: $\mathrm{C}_{\min }=\mathrm{x}_{0}-2 \mathrm{~b}$ e $\mathrm{C}_{\max }=\mathrm{x}_{0}+$ 2b. $\mathrm{A}_{\min }$ indica o momento na curva de acúmulo em que se iniciam os acúmulos mais expressivos e a $\mathrm{C}_{\max }$ o instante em que o acúmulo dos elementos começa a se estabilizar.

2) Gaussiano com três parâmetros:

$$
Y=a e^{\left[-0,5\left(\frac{x-x_{0}}{b}\right)^{2}\right]}
$$

Onde, $\mathrm{a}=$ corresponde ao valor de máximo acúmulo; $\mathrm{x}_{0}=$ corresponde ao valor de $\mathrm{x}$, em DAE, que proporciona o máximo em $\mathrm{y}$; e $\mathrm{b}=$ corresponde 
à amplitude no valor de $\mathrm{x}$, em DAE, entre o ponto de inflexão e o ponto de máximo.

3) Crescimento exponencial com três parâmetros:

$$
\mathrm{Y}=\mathrm{y}_{0}+\mathbf{a} e^{\mathrm{bx}}
$$

Onde, $\mathrm{y}_{0}=$ assíntota; $\mathrm{a}=$ amplitude de crescimento; $\mathrm{x}$ $=$ dias após a emergência, e $\mathrm{b}=$ taxa de crescimento.

4) Para o acúmulo de nutrientes nas panículas e grãos utilizou-se regressão linear.

Decidiu-se por considerar a exportação de nutrientes levando-se em conta a colheita, apenas dos colmos e também, de colmos e grãos.

\section{Resultados e Discussão}

Para o acúmulo de matéria seca total, foi possível ajustar para as cultivares CVSW80007 e CVSW80147 o modelo logístico (Figura 1-A, B), demonstrando que estas provavelmente tenham ciclo mais curto que as 'CVSW82028' e 'CVSW82158' (Figura 1-C, D), as quais ajustaram se ao modelo de crescimento exponencial. É notável também que o acúmulo de matéria seca nas folhas das duas cultivares citadas primeiramente, começa a se estabilizar dias antes do que a cultivar CVSW82028 (Tabela 1), podendo-se ressaltar ainda que para a cultivar CVSW82158 o melhor modelo ajustado para o acúmulo neste órgão da planta foi o de crescimento exponencial (Figura 1-, D).

Figura 1. Acúmulo de matéria seca pelos híbridos de sorgo sacarino durante o ciclo da planta.
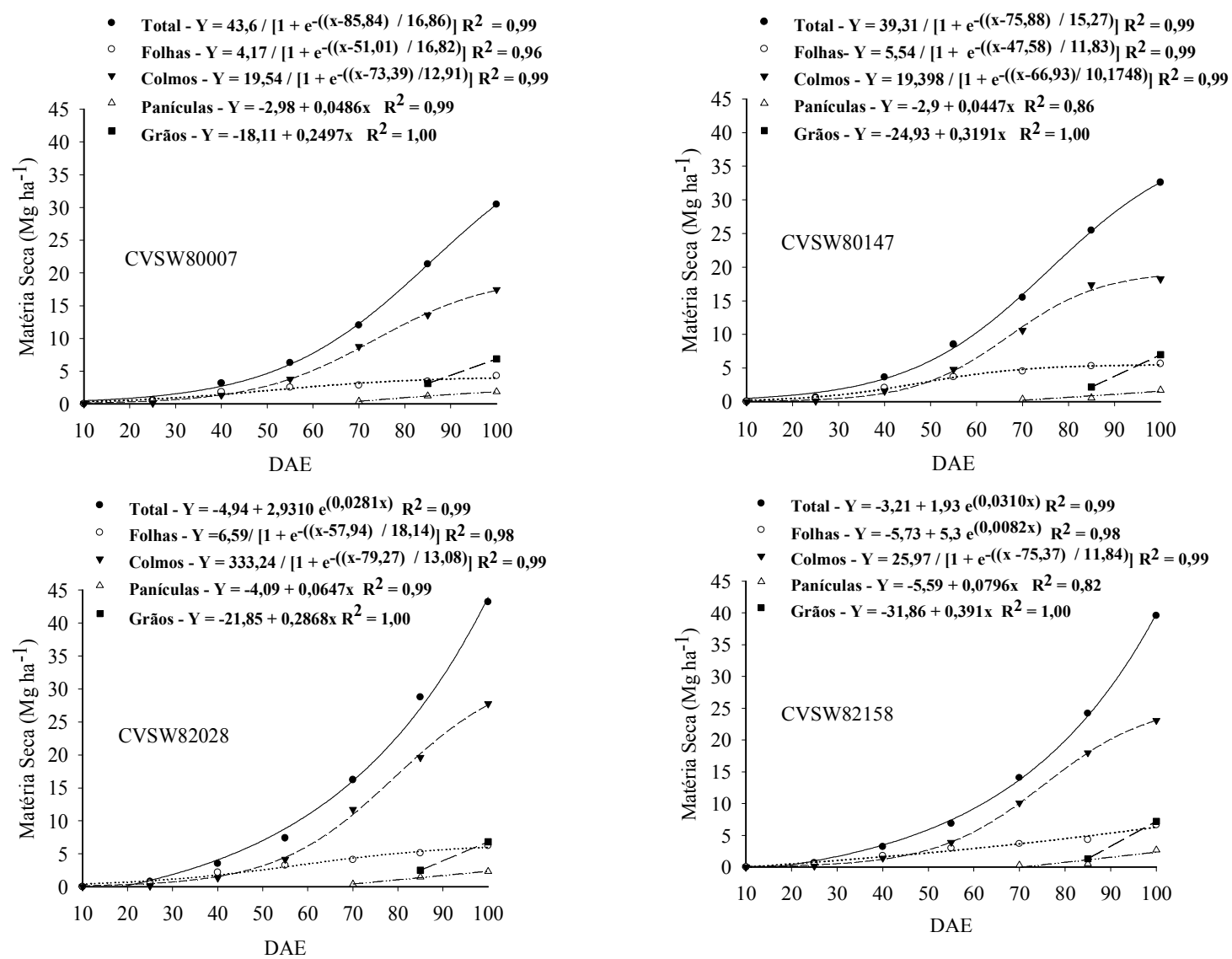

Fonte: Elaboração dos autores. 
Tabela 1. Curvatura mínima e máxima para o acúmulo de matéria seca, nitrogênio, fósforo e potássio.

\begin{tabular}{|c|c|c|c|c|c|c|c|c|c|}
\hline \multirow[b]{2}{*}{ Cultivares } & & \multicolumn{2}{|c|}{ Matéria seca } & \multicolumn{2}{|c|}{ Nitrogênio } & \multicolumn{2}{|c|}{ Fósforo } & \multicolumn{2}{|c|}{ Potássio } \\
\hline & & $\mathrm{C}_{\min }$ & $\mathrm{C}_{\max }$ & $\mathrm{C}_{\min }$ & $\mathrm{C}_{\mathrm{max}}$ & $\mathrm{C}_{\min }$ & $\mathrm{C}_{\max }$ & $\mathrm{C}_{\min }$ & $\mathrm{C}_{\max }$ \\
\hline \multicolumn{10}{|c|}{ DAE } \\
\hline \multirow{3}{*}{ CVSW80007 } & Total & 52 & $--^{1}$ & 33 & -- & 42 & 90 & 22 & 93 \\
\hline & Folhas & 17 & 85 & 19 & 53 & $--^{2}$ & --- & 24 & 26 \\
\hline & Colmos & 48 & 99 & 37 & 67 & --- & --- & 30 & 88 \\
\hline \multirow{3}{*}{ CVSW80147 } & Total & 45 & -- & 29 & 96 & --- & --- & --- & --- \\
\hline & Folhas & 24 & 71 & --- & --- & --- & --- & --- & --- \\
\hline & Colmos & 47 & 87 & --- & --- & --- & --- & --- & --- \\
\hline \multirow{3}{*}{ CVSW82028 } & Total & --- & --- & --- & --- & --- & --- & 32 & -- \\
\hline & Folhas & 22 & 94 & 21 & 69 & 24 & 62 & 13 & 50 \\
\hline & Colmos & 53 & -- & 30 & 89 & 43 & 79 & 41 & -- \\
\hline \multirow{3}{*}{ CVSW82158 } & Total & --- & --- & --- & --- & --- & --- & --- & --- \\
\hline & Folhas & --- & --- & 15 & 81 & 25 & 61 & 14 & 50 \\
\hline & Colmos & 52 & 99 & 28 & 80 & --- & --- & --- & --- \\
\hline
\end{tabular}

${ }^{1} \mathrm{Ac}_{\text {max }}$ calculado ficou acíma de 100 DAE.

${ }^{2}$ Não foi possível calcular os $\mathrm{C}_{\min }$ e $\mathrm{C}_{\max }$.

Fonte: Elaboração dos autores.

Os períodos nos quais o acúmulo de matéria seca nos colmos começa a se estabilizar (Cmax) obtidos para as cultivares CVSW80007, CVSW80147 e CVSW82158 (Tabela 1), foram respectivamente de 99, 87 e 99 DAE e corrobora com os observados por Klink (2010) sendo que este relata que a máxima produção de colmos pelas cultivares CVSW80007 e CVSW80147 é atingida aproximadamente aos 100 DAE.

A maior produção de biomassa seca foi obtida pelo híbrido CVSW82028 (Figura 1-C). Wortmann et al. (2010), trabalhando com diferentes cultivares, doses de $\mathrm{N}$ e densidade populacional, alcançaram

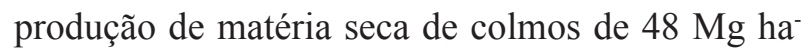
1. Monteiro, Havrland e Inanova (2012) relataram produtividades de matéria seca total em torno de 35 $\mathrm{Mg} \mathrm{ha}^{-1}$, ressaltando a importância do sorgo sacarino pela alta capacidade de produção de biomassa em um período curto de tempo (quatro meses). Já a matéria seca de grãos obtida pelas cultivares (em torno de $7 \mathrm{Mg} \mathrm{ha}^{-1}$ (Figura 1)) está acima do observado por Rosolem e Malavolta (1981a) que foi de 2,2 $\mathrm{Mg} \mathrm{ha}^{-1}$ para a variedade Rio e $2,5 \mathrm{Mg} \mathrm{ha}^{-1}$ para a Brandes. Singh et al. (2012), observaram para as variedades M-81E e Dale, matéria seca de grãos de 2,33 e 3,41 Mg ha ${ }^{-1}$, respectivamente. Desta forma podese constatar que, apesar da especialidade da planta ser a produção de colmos, os híbridos estudados produzem também quantidades relevantes de grãos. Esse é um fator importante a ser levado em consideração, tendo em vista que o peso dos grãos pode favorecer o acamamento das plantas, pois, o sorgo sacarino é uma planta de porte alto podendo atingir de acordo com Monteiro; Havrland e Inanova (2012) mais de 3,5 $\mathrm{m}$ de altura.

Em geral, os colmos corresponderam a $60 \%$ do total de matéria seca acumulada (Figura 2). Esses resultados são semelhantes aos observados por Rosolem e Malavolta (1981b). No entanto, em outros trabalhos (SINGH et al., 2012; MONTEIRO; HAVRLAND; INANOVA, 2012) os colmos representaram mais de $70 \%$ do total da biomassa seca produzida. 
Figura 2. Partição de matéria seca e macronutrientes pelo sorgo sacarino aos 100 dias após a emergência.
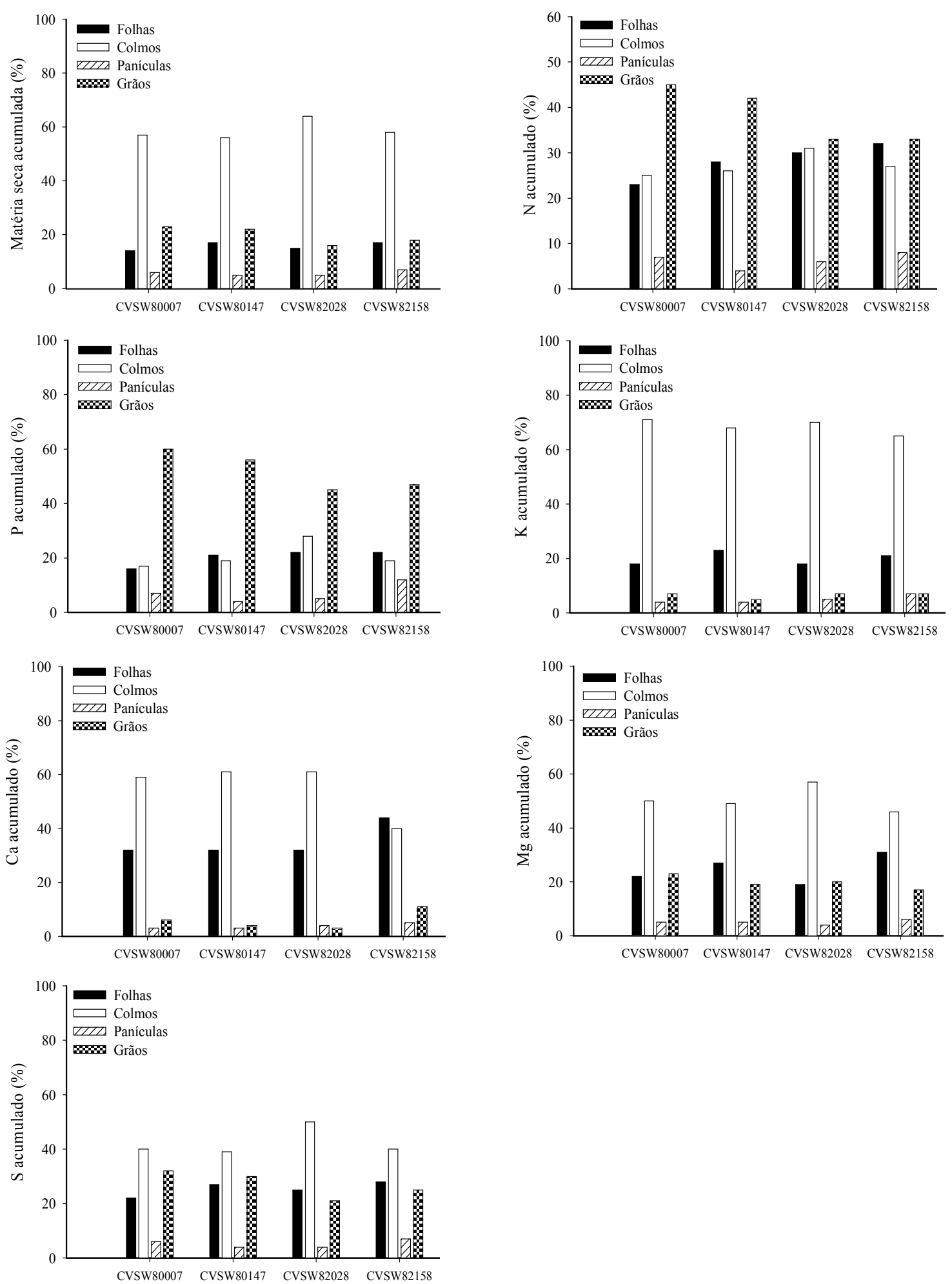

Fonte: Elaboração dos autores. 
As curvas de acúmulo total de nitrogênio, fósforo e potássio, seguiram a mesma tendência que as de matéria seca (Figuras 3, 4 e 5). Deve-se ressaltar, entretanto, que o início do período crítico de acúmulo $\left(\mathrm{C}_{\min }-\mathrm{C}_{\max }\right)$ de $\mathrm{N}$ nas cultivares CVSW80007 e CVSW80147, e de K na 'CVSW80007' ocorreu aos 33, 29 e 32 DAE, respectivamente, tendo, portanto iniciado mais cedo que o de matéria seca total (Tabela 1). A 'CVSW80147' é a única em que foi atingido o acúmulo máximo estimado de fósforo e potássio, tendo essa data ocorrido aproximadamente aos 90 DAE (Figura 4-B e 5-B). Isso demonstra que esta cultivar tem o ciclo mais curto do que a CVSW80007, o que pode ser reafirmado ao se observar que o início do período de maior incremento de matéria seca total se dá aos $45 \mathrm{DAE}$ para a cultivar CVSW80147 e aos 52 DAE para a 'CVSW80007' (Tabela 1) e também que o acúmulo de matéria seca em folhas e colmos começa a se estabilizar 14 e 12 dias antes, respectivamente, na 'CVSW80147' (Tabela 1).

Figura 3. Acúmulo de nitrogênio pelos híbridos de sorgo sacarino durante o ciclo da planta.
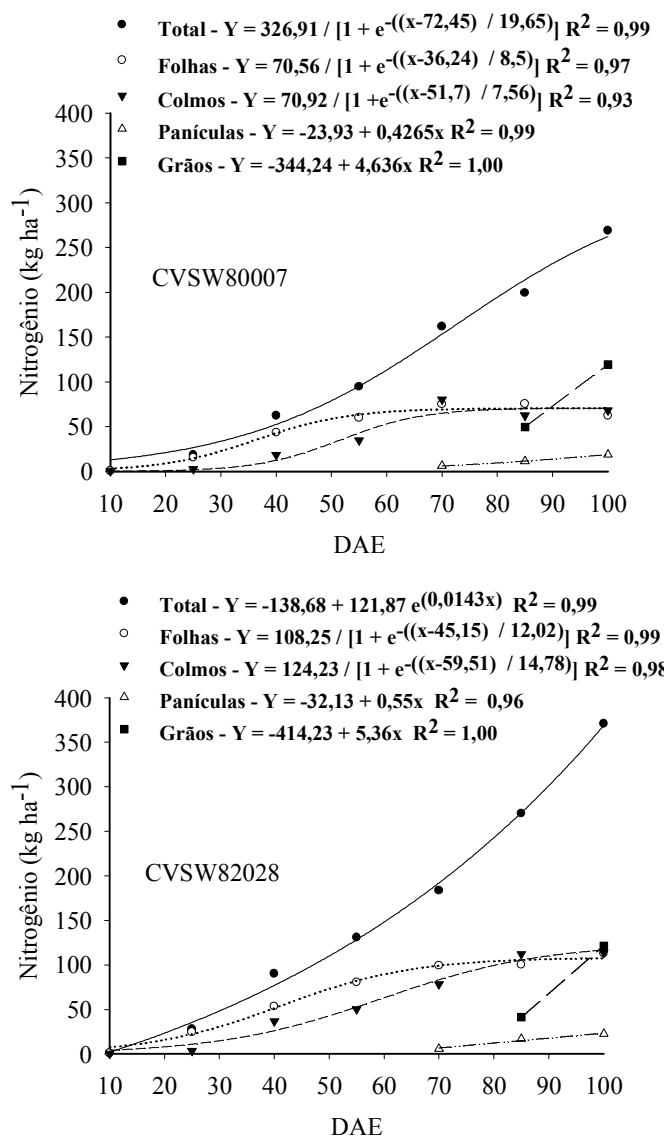

Fonte: Elaboração dos autores.

Em função da necessidade do parcelamento da adubação nitrogenada, devido a problemas de lixiviação e, considerando também o início do período de maior demanda de $\mathrm{N}$ (total) nas cultivares CVSW80007 e CVSW80147 (Tabela
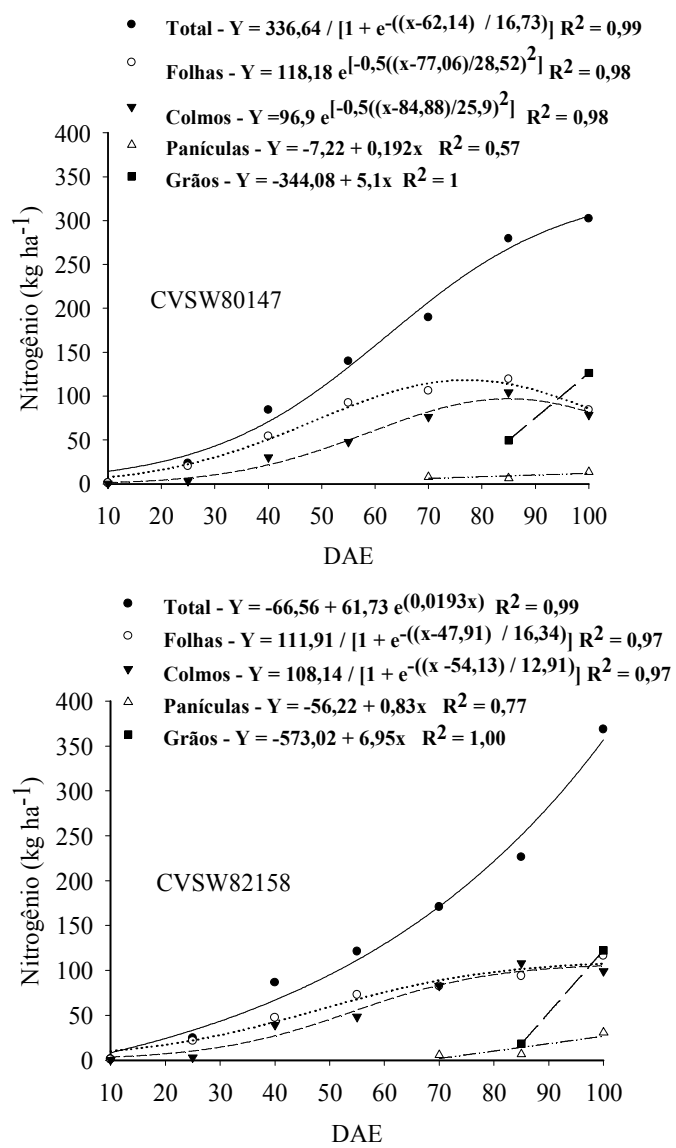

1), pode-se sugerir que a adubação de cobertura com este nutriente seja realizada aproximadamente aos 20 DAE. Desta forma, haverá um intervalo de tempo para que o adubo aplicado passe pelo processo de mineralização, estando disponível 
quando iniciar o período de maior acúmulo de $\mathrm{N}$ pelas plantas. Considerando, neste caso, que o adubo utilizado seja a ureia, tendo em vista que este é o fertilizante nitrogenado mais utilizado na agricultura (ESPINDULA et al., 2013).

Como o acumulo mais expressivo de potássio ocorre após os 20 DAE nas cultivares CVSW80007 e CVSW82028 e tomando por base que boa parte da adubação potássica também é realizada em cobertura, sugere-se que este seja aplicado juntamente com o nitrogênio, evitando maiores custos com outra aplicação.
Ainda quanto aos períodos de maior acúmulo de nitrogênio nas folhas e nos colmos, podemos observar que as cultivares CVSW82028 e CVSW82158 começam a estabilizar o acúmulo mais tardiamente, com Cmax de 69 e 81 DAE para folhas e 89 e 80 para colmos, respectivamente, com 16 e 28 (folhas) e 22 e 13 (colmos) dias após a cultivar CVSW80007 (Tabela 1). É possível notar também que, na 'CVSW80147' ocorreu redistribuição de $\mathrm{N}$ das folhas e colmos para os grãos após 77 e 85 DAE, respectivamente (Figura 3-B).

Figura 4. Acúmulo de fósforo pelos híbridos de sorgo sacarino durante o ciclo da planta.
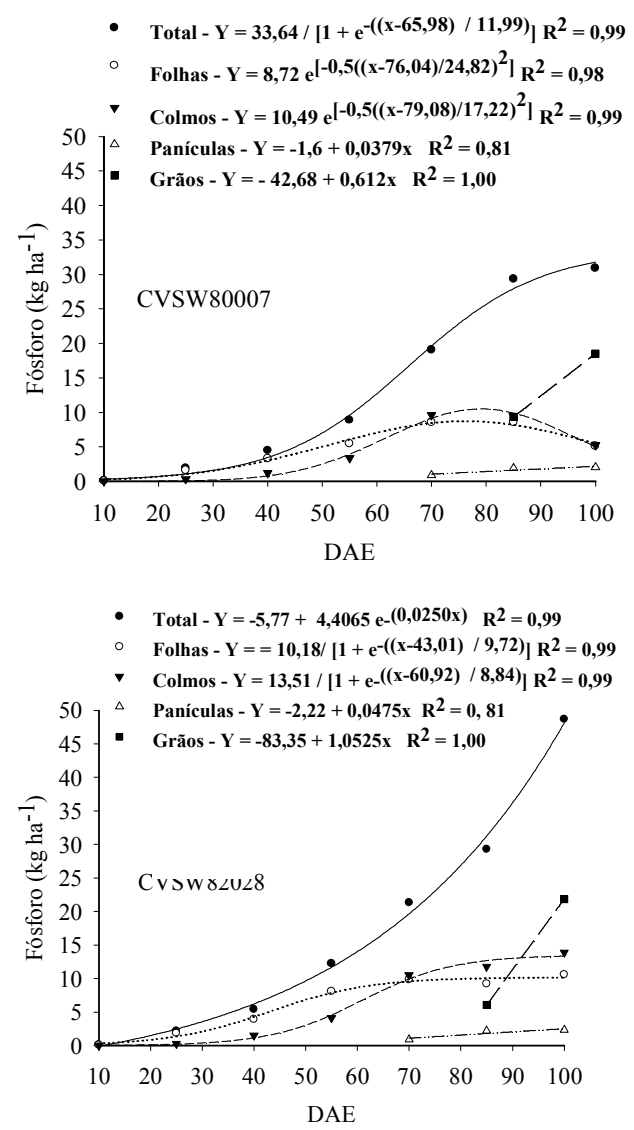

Fonte: Elaboração dos autores.
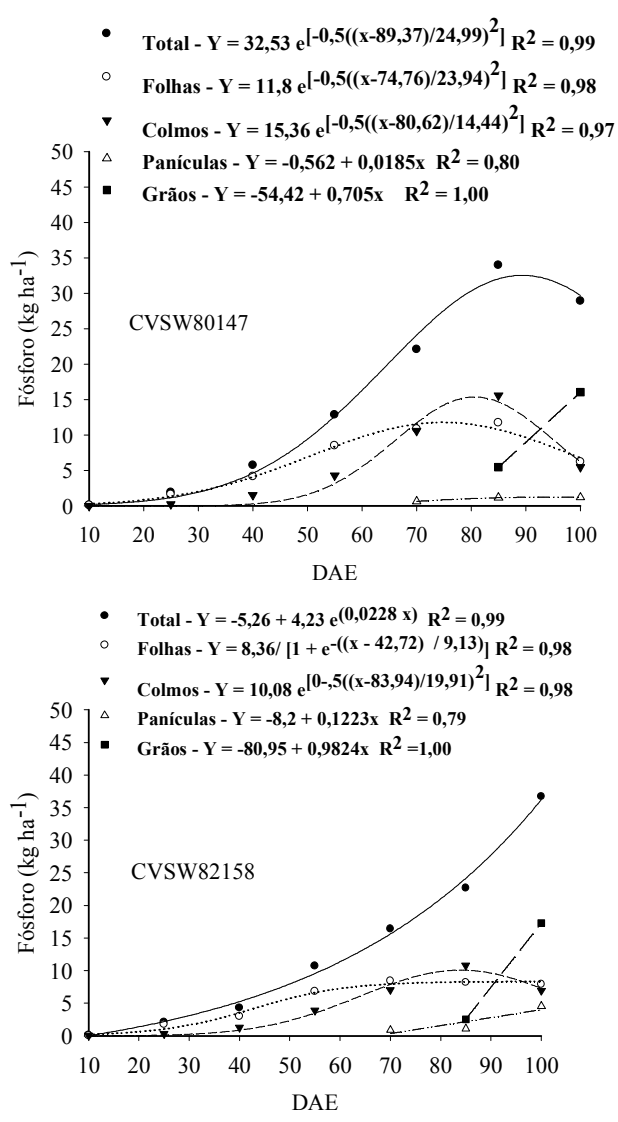

Os híbridos CVSW82028 e CVSW82158 Nos 'CVSW80007' e 'CVSW80147', foi notada apresentaram comportamento similar em relação a redistribuição de $\mathrm{P}$ das folhas e colmos para os acumulação de fósforo nas folhas (Figura 4-C, D). grãos (Figura 4-A, B), já no 'CVSW82158' esta 
ocorre apenas dos colmos (Figura 4, D). Rosolem e Malavolta(1981b), trabalhando com duas variedades de sorgo sacarino, observaram redistribuição de $\mathrm{N} \mathrm{e}$ $\mathrm{P}$ das folhas e colmos para os grãos.

Pela figura 4-A nota-se que na cultivar CVSW80007 o acúmulo de fósforo nos grãos teve início mais cedo, pois aos 85 DAE esta já tinha acumulado metade de todo o fósforo dos grãos, característica não observada nas outras cultivares. Esta cultivar apresentou esse mesmo comportamento quanto ao acúmulo de matéria seca nos grãos, demonstrando assim que o enchimento de grãos ocorreu mais precocemente na mesma.

Os grãos concentraram a maior parte da quantidade extraída de fósforo (Figura 2). No estudo de Rosolem e Malavolta (1981b) os grãos foram responsáveis pelo acúmulo de 42 e $53 \%$, do total de P absorvido, respectivamente, para duas variedades. Neste estudo, os híbridos testados demonstraram absorver maiores quantidades de fósforo (Tabela 2) que as variedades avaliadas por Rosolem e Malavolta (1981b), que acumularam 15 e $20 \mathrm{~kg}$ $\mathrm{ha}^{-1}$ de $\mathrm{P}$ em 14,6 e 16,3 toneladas de matéria seca, respectivamente, ou seja, 1,03 e 1,23 kg de fósforo extraído para cada $\mathrm{Mg}$ de matéria seca produzida. Em nosso trabalho, os cultivares CVSW80007, CVSW80147, CVSW82028 e CVSW82158 extraíram do solo 1,$03 ; 0,88 ; 1,12$ e $0,92 \mathrm{~kg}$ de fósforo por $\mathrm{Mg}$ de matéria seca, respectivamente. O 'CVSW82158' merece destaque por ter utilizado menos P que os CVSW80007 e CVSW82028, entretanto, produziu uma alta quantidade de matéria seca (40 $\left.\mathrm{Mg} \mathrm{ha}^{-1}\right)$ (Tabela 2).

Figura 5. Acúmulo de potássio pelos híbridos de sorgo sacarino durante o ciclo da planta.
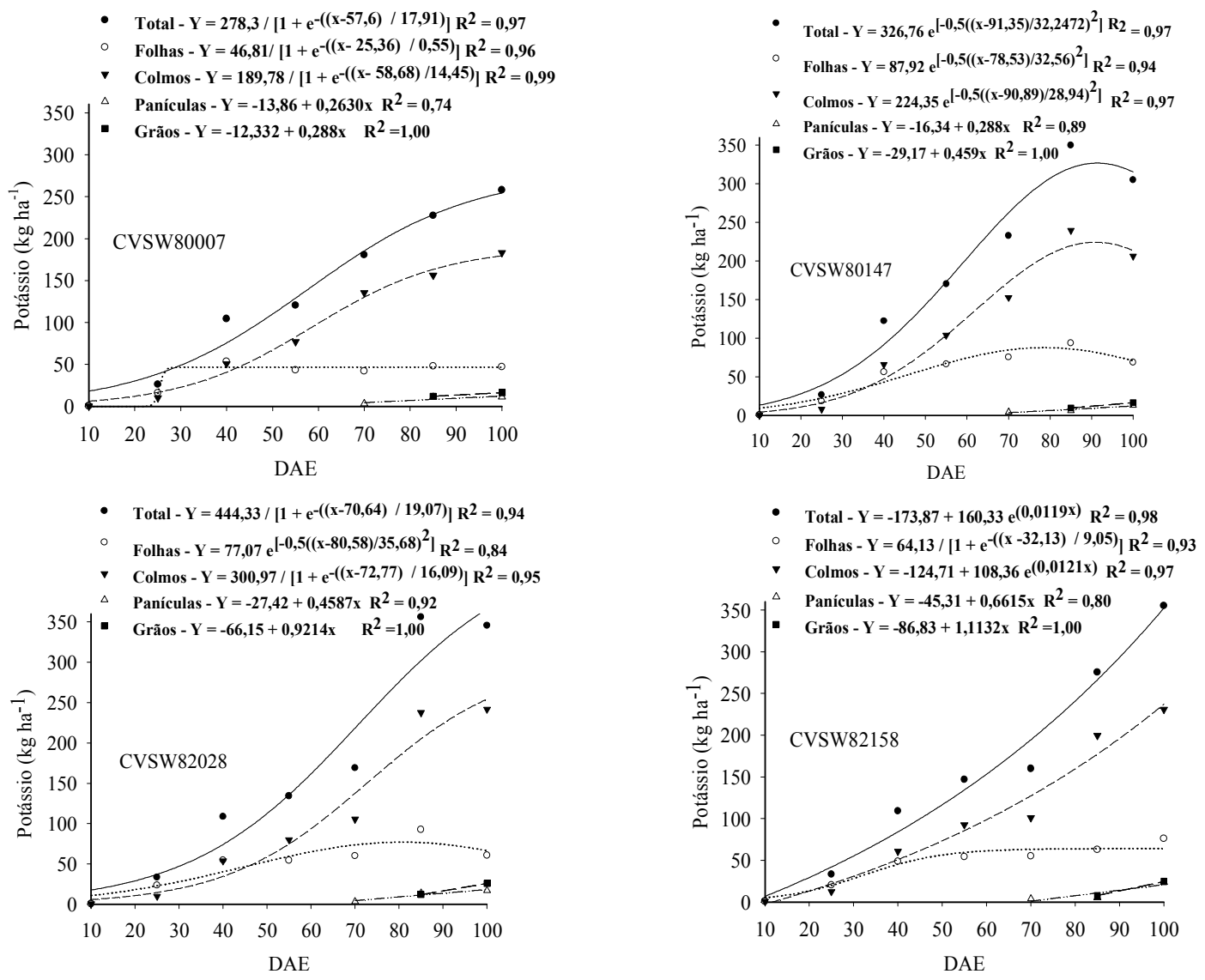

Fonte: Elaboração dos autores. 
Pela tabela 2, pode-se observar que o total acumulado de fósforo variou entre 29 e $49 \mathrm{~kg} \mathrm{ha}^{-1}$, e a produtividade de 30 a $44 \mathrm{Mg}$ de matéria seca por hectare. No trabalho de Han et al. (2011) o acúmulo variou de 30 a $58 \mathrm{~kg} \mathrm{ha}^{-1}$ de $\mathrm{P}$ dependendo do cultivar utilizado, entretanto, estes autores não apresentaram a produção de matéria seca dos cultivares.

Para o potássio, as duas variedades avaliadas por Rosolem e Malavolta (1981b), acumularam 146 e $200 \mathrm{~kg} \mathrm{ha}^{-1}$, o que significa que estas absorveram para cada tonelada de matéria seca produzida, 10 e $12,27 \mathrm{~kg}$ de $\mathrm{K}$, respectivamente. Neste experimento, foi extraído 8,$6 ; 9,2 ; 7,9$ e 8,9 $\mathrm{kg}$ de $\mathrm{K}$ por cada
Mg de matéria seca, pelos cultivares CVSW80007, CVSW80147, CVSW82028 e CVSW82158, ou seja, os híbridos testados demonstraram exigir menores quantidades de potássio por cada $\mathrm{Mg}$ de matéria seca produzida que as variedades avaliadas por aqueles autores. Todavia, devido à alta produtividade obtida pelos híbridos, as quantidades extraídas de $\mathrm{K}$ do solo foram maiores, variando de 258 a $355 \mathrm{~kg} \mathrm{ha}^{-1}$, dependendo do cultivar (Tabela 2). A quantidade de $\mathrm{K}$ acumulado pelos híbridos foi maior também que o observado por Han et al. (2011) que variou de 109 a $209 \mathrm{~kg} \mathrm{ha}^{-1}$, dependendo do cultivar.

Tabela 2. Acúmulo total de matéria seca e macronutrientes e exportação de macronutrientes por cultivares de sorgo sacarino em $\mathrm{kg} \mathrm{ha}^{-1}$ e porcentagem exportada.

\begin{tabular}{|c|c|c|c|c|c|c|c|}
\hline \multicolumn{8}{|c|}{ Acúmulo total } \\
\hline Cultivares & Matéria seca & $\mathrm{N}$ & $\mathrm{P}$ & $\mathrm{K}$ & $\mathrm{Ca}$ & $\mathrm{Mg}$ & $\mathrm{S}$ \\
\hline & $\mathrm{Mg} \mathrm{ha}^{-1}$ & & & & $\mathrm{~g} \mathrm{ha}^{-1}$ & & \\
\hline CVSW80007 & 30 & 269 & 31 & 258 & 65 & 46 & 22 \\
\hline CVSW80147 & 33 & 302 & 29 & 305 & 92 & 44 & 23 \\
\hline CVSW82028 & 44 & 371 & 49 & 346 & 68 & 59 & 33 \\
\hline CVSW82158 & 40 & 369 & 37 & 355 & 76 & 55 & 29 \\
\hline \multicolumn{8}{|c|}{ Exportação (colmos) } \\
\hline Cultivares & $\mathrm{N}$ & & $\mathrm{P}$ & $\mathrm{K}$ & $\mathrm{Ca}$ & $\mathrm{Mg}$ & $\mathrm{S}$ \\
\hline \multicolumn{8}{|c|}{$\mathrm{kg} \mathrm{ha}^{-1}$} \\
\hline CVSW80007 & $68(25 \%)$ & & $5(16 \%)$ & $183(71 \%)$ & $38(59 \%)$ & $23(50 \%)$ & $9(41 \%)$ \\
\hline CVSW80147 & $78(26 \%)$ & & $5(17 \%)$ & $206(68 \%)$ & $57(62 \%)$ & $22(50 \%)$ & $9(39 \%)$ \\
\hline CVSW82028 & $114(31 \%)$ & & $14(29 \%)$ & $242(70 \%)$ & $42(62 \%)$ & $33(56 \%)$ & $17(51 \%)$ \\
\hline CVSW82158 & $99(27 \%)$ & & $7(19 \%)$ & $231(65 \%)$ & $30(40 \%)$ & $25(46 \%)$ & $12(41 \%)$ \\
\hline \multicolumn{8}{|c|}{ Exportação (colmos + grãos) } \\
\hline Cultivares & $\mathrm{N}$ & & $\mathrm{P}$ & $\mathrm{K}$ & $\mathrm{Ca}$ & $\mathrm{Mg}$ & $\mathrm{S}$ \\
\hline \multicolumn{8}{|c|}{$\mathrm{kg} \mathrm{ha}^{-1}$} \\
\hline CVSW80007 & $187(70 \%)$ & & $24(74 \%)$ & $199(77 \%)$ & $42(65 \%)$ & $33(72 \%)$ & $16(73 \%)$ \\
\hline CVSW80147 & $204(68 \%)$ & & $21(72 \%)$ & $223(73 \%)$ & $61(66 \%)$ & $30(68 \%)$ & $16(70 \%)$ \\
\hline CVSW82028 & $236(64 \%)$ & & $36(74 \%)$ & $268(78 \%)$ & $44(65 \%)$ & $45(76 \%)$ & $24(73 \%)$ \\
\hline CVSW82158 & $221(60 \%)$ & & $24(65 \%)$ & $255(72 \%)$ & $39(51 \%)$ & $34(62 \%)$ & $19(66 \%)$ \\
\hline
\end{tabular}

Fonte: Elaboração dos autores.

Verificou-se que ocorreu redistribuição de K das folhas e colmos na cultivar CVSW80147 (Figura 5-B) e das folhas na 'CVSW82028' (Figura 5-C) que provavelmente tenha sido redirecionado para panículas e grãos, enquanto na 'CVSW80007' (Figura 5-A), há um intervalo de tempo muito pequeno entre o $\mathrm{C}_{\min }$ e $\mathrm{C}_{\max }$ determinados. Isso se deve ao fato de que esta cultivar acumula pouco $\mathrm{K}$ até os $20 \mathrm{DAE}$, havendo um rápido aumento na absorção e, logo em seguida, o acúmulo começa a estabilizar. Na cultivar CVSW82158 (Figura 5-D), expressivos acúmulos de potássio nos colmos 
foram observados até os 100 DAE. Entretanto, na 'CVSW80007' o acúmulo permanece estável após os 88 DAE (Figura 5-A).

O total de $\mathrm{N}$ absorvido pelos híbridos de sorgo sacarino (Figura 3; Tabela 2) é superior ao observado por Singh et al. (2012) que foi de $136 \mathrm{~kg} \mathrm{ha}^{-1}$. No entanto, a produtividade obtida por estes autores foi baixa $\left(19,5 \mathrm{Mg} \mathrm{ha}^{-1}\right)$, comparada as produções alcançadas pelos híbridos, nesse trabalho. Ainda sobre o trabalho destes autores, para cada $\mathrm{Mg}$ de matéria seca produzida foram extraídos $6,97 \mathrm{~kg}$ de N. Para os híbridos CVSW80007, CVSW80147, CVSW82028 e CVSW82158 foram necessários 9; 10,$07 ; 8,4$ e 9,2 kg de $\mathrm{N}$, respectivamente, por $\mathrm{Mg}$ de matéria seca produzida.

As cultivares CVSW80007 e CVSW80147, apesar da menor quantidade de matéria seca total produzida, acumularam nos grãos quantidades de $\mathrm{N}$ semelhantes às outras (Figura 3). Nesse sentido, o percentual de acúmulo nos grãos foi bem maior nestas cultivares, ao passo que para as outras duas, mesmo os grãos tendo alocado a maior quantidade de $\mathrm{N}$, houve maior equilíbrio na distribuição deste para os órgãos folhas, colmos e grãos, pois estas obtiveram percentuais de acúmulos semelhantes (em torno de 30\%) (Figura 2). Esta característica observada de maior acúmulo de nitrogênio nos grãos dos híbridos é distinta das variedades estudas por Rosolem e Malavolta (1981b) sendo que a maior parte do $\mathrm{N}$ ficou concentrada nos colmos.

Todas as cultivares apresentaram curvas de acúmulo de Ca semelhantes tanto para o total, como nos colmos (Figura 6). Já nas folhas, a cultivar CVSW82158 (Figura 6-D), da mesma forma que com a matéria seca (Figura 1-D), foi a única que se ajustou a um modelo de curva de crescimento exponencial. Com o $\mathrm{Mg}$, o acúmulo máximo estimado (total) foi alcançado aos 85 DAE pela cultivar CVSW80147 (Figura 7-B). Nesta cultivar foi observado redistribuição de $\mathrm{Mg}$ de colmos e folhas para os grãos e na 'CVSW82028' (Figura 7-C) apenas das folhas para os grãos. O período crítico de acúmulo nas folhas da cultivar CVSW82158 estendeu-se dos 30 até 94 DAE (Tabela 3).

O sorgo sacarino acumulou quantidades de $\mathrm{Ca}$ menores do que a observada por Franco (2011) para um híbrido de sorgo forrageiro que acumulou $104 \mathrm{~kg}$ $\mathrm{ha}^{-1}$ de $\mathrm{Ca}$, com uma produtividade de $18,3 \mathrm{Mg} \mathrm{ha}^{-1}$, representando uma extração de $5,7 \mathrm{~kg}$ de Ca por $\mathrm{Mg}$ de matéria seca produzida. As quantidades extraídas de $\mathrm{Ca}$ por cada $\mathrm{Mg}$ de matéria seca produzida foram: 2,2; 2,8; 1,5 e 1,9 kg, respectivamente, para os híbridos CVSW80007, CVSW80147, CVSW82028 e CVSW82158. Observa-se, portanto que a exigência em $\mathrm{Ca}$ pelo sorgo sacarino foi bem menor que a do sorgo forrageiro no trabalho de Franco (2011), com destaque para as cultivares CVSW82028 e CVSW82158 pela pouca quantidade extraída de Ca do solo, sobretudo, obtiveram uma alta produtividade de 44 e $40 \mathrm{Mg} \mathrm{ha}^{-1}$, respectivamente.

Ressalta-se ainda que, no trabalho deste autor, além do $\mathrm{Ca}$, as quantidade extraídas pelo sorgo forrageiro de $\mathrm{N}, \mathrm{P}$ e $\mathrm{K}$ por $\mathrm{Mg}$ de matéria seca foram maiores que as extraídas pelos híbridos de sorgo sacarino sendo estas 15,7; 18,09 e 2,66, respectivamente. Podemos salientar então, que estudos futuros que visem a utilização dos sorgo sacarino também para a alimentação animal, sejam muito interessantes, tendo em vista que culturas altamente produtivas e com maior eficiência de utilização de nutrientes são importantes para a sustentabilidade do sistema de produção.

Rosolem e Malavolta (1981b) relataram que, apesar das quantidades acumuladas de $\mathrm{Ca}$ e $\mathrm{Mg}$ e também a partição nas diferentes partes da planta terem sido diferentes, as curvas de acúmulo em função da idade da planta de sorgo sacarino foram bastante parecidas para estes dois nutrientes, já neste experimento ocorreu exatamente o contrário, pois, os padrões de acúmulo de cálcio e magnésio foram bastante distintos como pode ser observado nas Figuras 6 e 7. 
Figura 6. Acúmulo de cálcio pelos híbridos de sorgo sacarino durante o ciclo da planta.
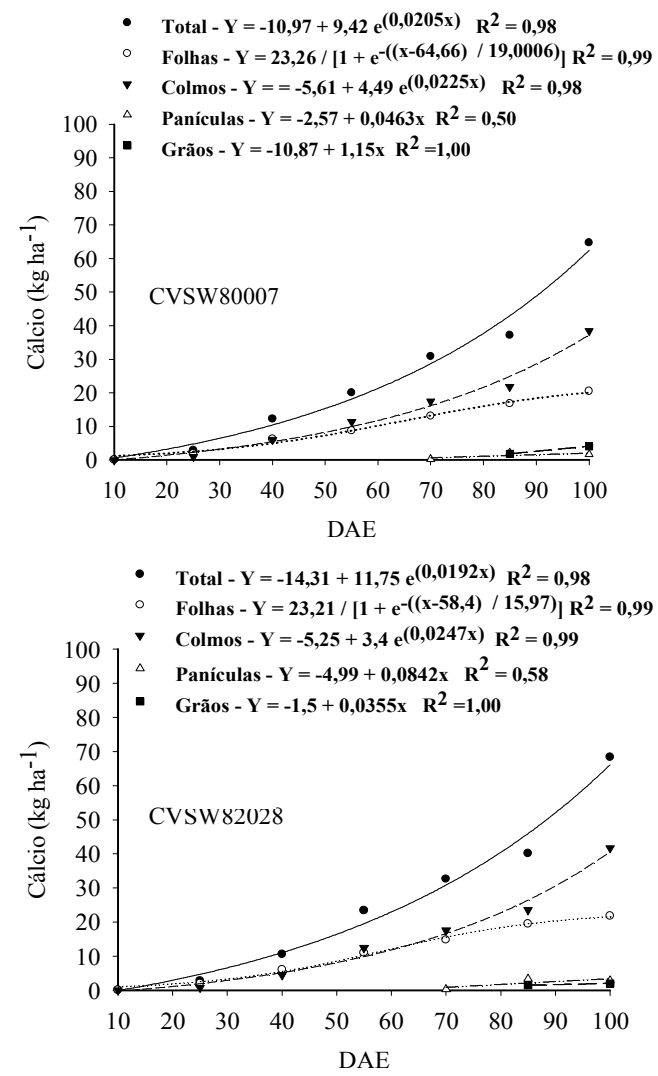

Fonte: Elaboração dos autores.

Os padrões de acúmulo total de S (Figura 8) foram similares ao de matéria seca (Figura 1), ocorrendo nas folhas as mesmas tendências observadas para o N (Figura 3 e Tabela 3). Nos colmos, os incrementos foram mais acentuados nas cultivares CVSW82028 e CVSW82158 até os 100 DAE (Figura 8-C, D).

As quantidades acumuladas de $\mathrm{S}$ pelos híbridos CVSW80007 e CVSW80147 (Figura 8-A, B) assemelham-se ao obtido pelo sorgo forrageiro
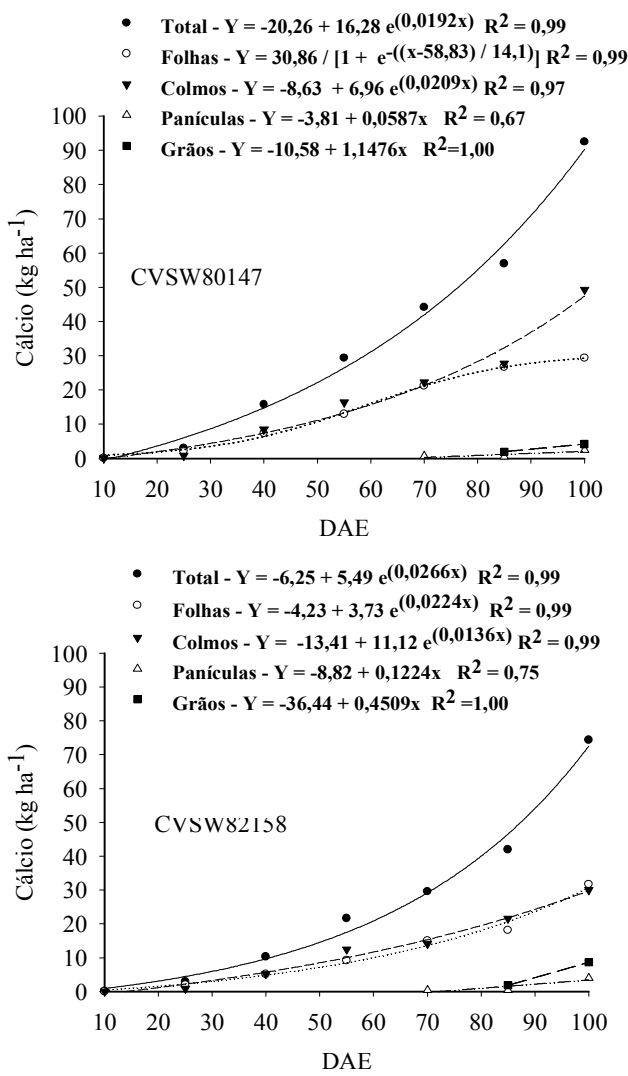

e granífero (FRANCO, 2011), enquanto que as cultivares CVSW82028 e CVSW82158 acumularam mais $\mathrm{S}$ do que o observado por aquele autor. Pode-se dizer ainda que, o sorgo sacarino absorve quantidades de $\mathrm{S}$ semelhantes a outras culturas como o milho. Nesta cultura, por exemplo, Von Pinho et al. (2009) verificaram para dois híbridos acúmulos de 22 e $34 \mathrm{~kg} \mathrm{ha}^{-1}$ de $\mathrm{S}$. 
Figura 7. Acúmulo de magnésio pelos híbridos de sorgo sacarino durante o ciclo da planta.
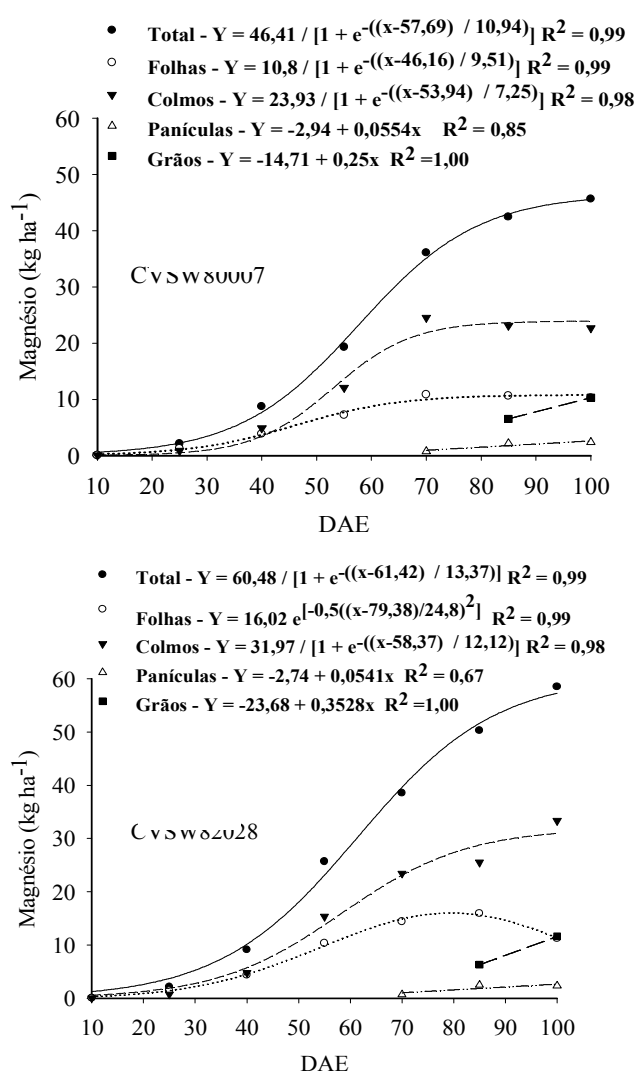

Fonte: Elaboração dos autores.

As quantidades acumuladas de $\mathrm{S}$ pelos híbridos CVSW80007 e CVSW80147 (Figura 8-A, B) assemelham-se ao obtido pelo sorgo forrageiro e granífero (FRANCO, 2011), enquanto que as cultivares CVSW82028 e CVSW82158 acumularam mais $\mathrm{S}$ do que o observado por aquele autor. Pode-se dizer ainda que, o sorgo sacarino absorve quantidades de $\mathrm{S}$ semelhantes a outras culturas como o milho. Nesta cultura, por exemplo, Von Pinho et al. (2009) verificaram para dois híbridos acúmulos de 22 e $34 \mathrm{~kg} \mathrm{ha}^{-1}$ de $\mathrm{S}$.

A cultivar CVSW82028 foi responsável pelos maiores acúmulos totais de $\mathrm{N}, \mathrm{P}, \mathrm{Mg}$ e $\mathrm{S}$, enquanto a 'CVSW82158' acumulou a maior quantidade de K e a 'CVSW80147,' absorveu a maior quantidade de $\mathrm{Ca}$.

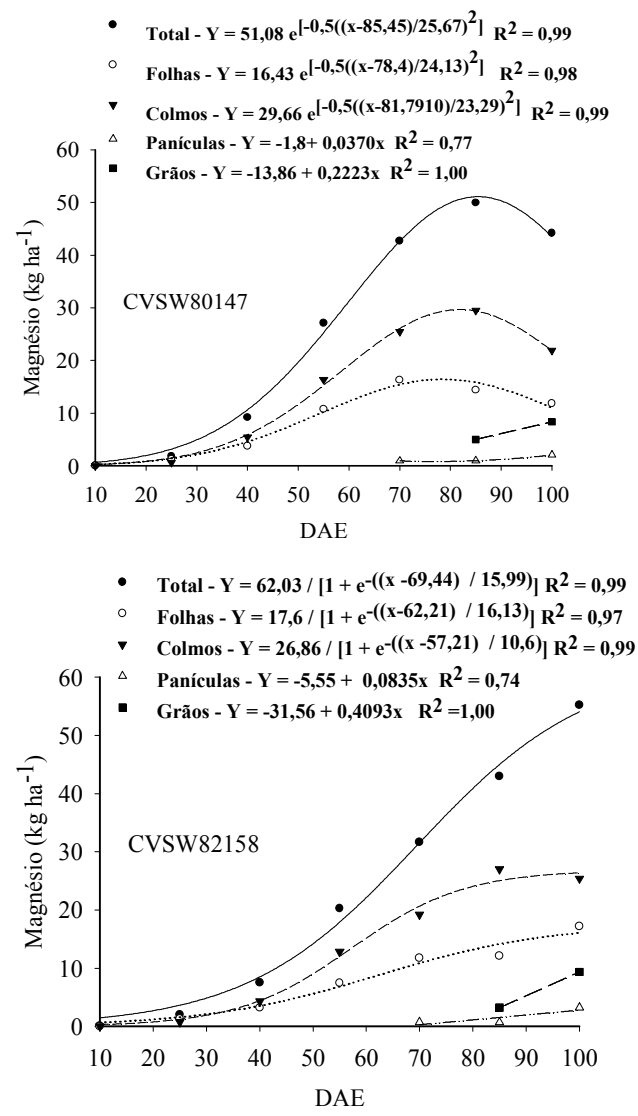

A maior parte do K, Ca, Mg e S absorvidos ficaram alocados nos colmos (Figura 2), com exceção da cultivar CVSW82158, que concentraram a maior parte de Ca nas folhas. Como no sorgo sacarino, o produto colhido é o colmo, a maior parte dos nutrientes extraídos é então exportada, como pode ser observado na Tabela 2. Os híbridos de sorgo sacarino demonstraram extrair altas quantidades de macronutrientes do solo, sendo as quantidades acumuladas de $\mathrm{N}$ e $\mathrm{P}$ maiores que o relatado para cana-de-açúcar (cana-planta) por Oliveira et al. (2011). Como são duas culturas que estarão inseridas no mesmo sistema de produção, com alta exigência nutricional, a reposição dos nutrientes através da adubação é extremamente importante. 
Tabela 3. Curvatura mínima e máxima para o acúmulo de cálcio, magnésio e enxofre.

\begin{tabular}{cccccccc}
\hline & & \multicolumn{2}{c}{ Cálcio } & \multicolumn{2}{c}{ Magnésio } & \multicolumn{2}{c}{ Enxofre } \\
\hline Cultivares & & $\mathrm{C}_{\min }$ & $\mathrm{C}_{\max }$ & $\mathrm{C}_{\min }$ & $\mathrm{C}_{\max }$ & $\mathrm{C}_{\min }$ & $\mathrm{C}_{\max }$ \\
\hline \multirow{3}{*}{ CVSW80007 } & & & $\mathrm{DAE}$ & & & \\
& Total & $---{ }^{-1}$ & --- & 36 & 80 & 37 & $-^{2}$ \\
& Folhas & 27 & -- & 27 & 65 & 15 & 57 \\
& Colmos & --- & --- & 39 & 68 & 36 & 81 \\
\hline \multirow{3}{*}{ CVSW80147 } & Total & --- & --- & --- & --- & 32 & 94 \\
& Folhas & 31 & 87 & --- & --- & --- & --- \\
& Colmos & --- & --- & --- & --- & 40 & 77 \\
\hline \multirow{2}{*}{ CVSW82028 } & Total & --- & --- & 35 & 88 & --- & --- \\
& Folhas & 26 & 90 & --- & --- & 17 & 74 \\
& Colmos & --- & --- & 34 & 83 & --- & --- \\
\hline \multirow{2}{*}{ CVSW82158 } & Total & --- & --- & 37 & -- & --- & --- \\
& Folhas & --- & --- & 30 & 94 & 14 & 77 \\
& Colmos & --- & --- & 36 & 78 & 43 & -- \\
\hline
\end{tabular}

${ }^{1}$ Não foi possível calcular as $\mathrm{C}_{\min }$ e $\mathrm{C}_{\max }$.

${ }^{2} \mathrm{~A} \mathrm{C}_{\max }$ calculado ficou acíma de $100 \mathrm{DAE}$.

Fonte: Elaboração dos autores.

Foi observada a mesma ordem decrescente de extração de macronutrientes para as cultivares CVSW80007, CSVW82028 e CVSW82158, sendo esta: $\mathrm{N}>\mathrm{K}>\mathrm{Ca}>\mathrm{Mg}>\mathrm{P}>\mathrm{S}$, e, na 'CVSW80147': $\mathrm{K}>\mathrm{N}>\mathrm{Ca}>\mathrm{Mg}>\mathrm{P}>\mathrm{S}$ (Tabela 2). Deve-se ressaltar, no entanto, que, em geral as quantidades extraídas de $\mathrm{N}$ e $\mathrm{K}$ pelas cultivares foram similares. No experimento de Rosolem e Malavolta (1981a), a ordem de extração de macronutrientes relatada foi a mesma que a obtida pela cultivar CVSW80147 neste experimento. Franco (2011), relatou a sequência $\mathrm{K}>\mathrm{N}>\mathrm{Ca}>\mathrm{P}>\mathrm{Mg}>\mathrm{S}$ para um híbrido de sorgo forrageiro e $\mathrm{N}>\mathrm{K}>\mathrm{Ca}>\mathrm{P}>\mathrm{Mg}>\mathrm{S}$ para o sorgo granífero.
A ordem decrescente de exportação de nutrientes, considerando somente os colmos, para todas as cultivares, foi $\mathrm{K}>\mathrm{N}>\mathrm{Ca}>\mathrm{Mg}>\mathrm{S}>\mathrm{P}$. Quando considerado colmo e grão dá-se a sequência $\mathrm{K}>\mathrm{N}>\mathrm{Ca}>\mathrm{Mg}>\mathrm{P}>\mathrm{S}$ para as cultivares $\mathrm{CVSW} 80007$, CVSW80147 e CVSW82158 e $\mathrm{K}>\mathrm{N}>\mathrm{Mg}>\mathrm{Ca}>\mathrm{P}>\mathrm{S}$ para a 'CVSW82028' (Tabela 2). A grande diferença quando se considera a colheita dos colmos e grãos são as maiores quantidades exportadas de nutrientes, principalmente $\mathrm{N}$ e $\mathrm{P}$ (Tabela 2 ), que poderiam retornar ao solo através da mineralização dos restos culturais. 
Figura 8. Acúmulo de enxofre pelos híbridos de sorgo sacarino durante o ciclo da planta.

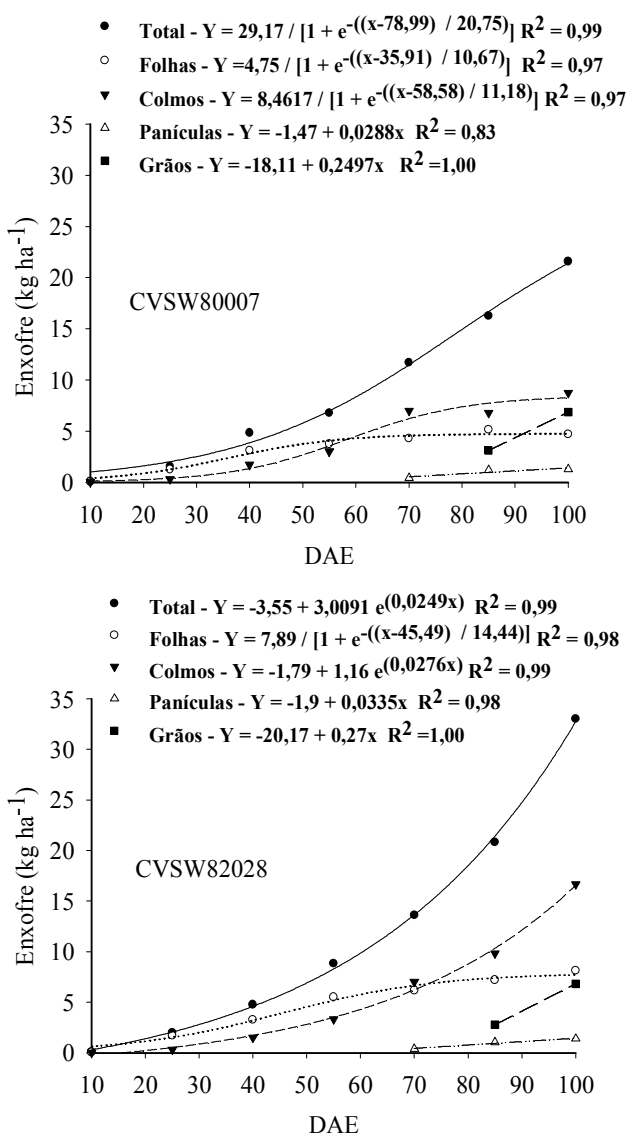

Fonte: Elaboração dos autores.

\section{Conclusão}

Os colmos acumulam maior percentual de $\mathrm{K}$, $\mathrm{Ca}, \mathrm{Mg}$ e $\mathrm{S}$ e os grãos maior de $\mathrm{N}$ e $\mathrm{P}$.

Há diferenças entre os cultivares de sorgo sacarino quanto ao acúmulo e exportação de macronutrientes.

Considerando a colheita apenas dos colmos, a ordem decrescente de exportação de macronutrientes é a mesma para todas as cultivares $(\mathrm{K}>\mathrm{N}>\mathrm{Ca}>\mathrm{Mg}>\mathrm{S}>\mathrm{P})$.

A sequência decrescente de exportação de macronutrientes considerando a colheita de colmos e grãos é: $\mathrm{K}>\mathrm{N}>\mathrm{Ca}>\mathrm{Mg}>\mathrm{P}>\mathrm{S}$ para os cultivares CVSW80007, CVSW80147 e CVSW82158 e $\mathrm{K}>\mathrm{N}>\mathrm{Mg}>\mathrm{Ca}>\mathrm{P}>\mathrm{S}$ para o cultivar CVSW82028.

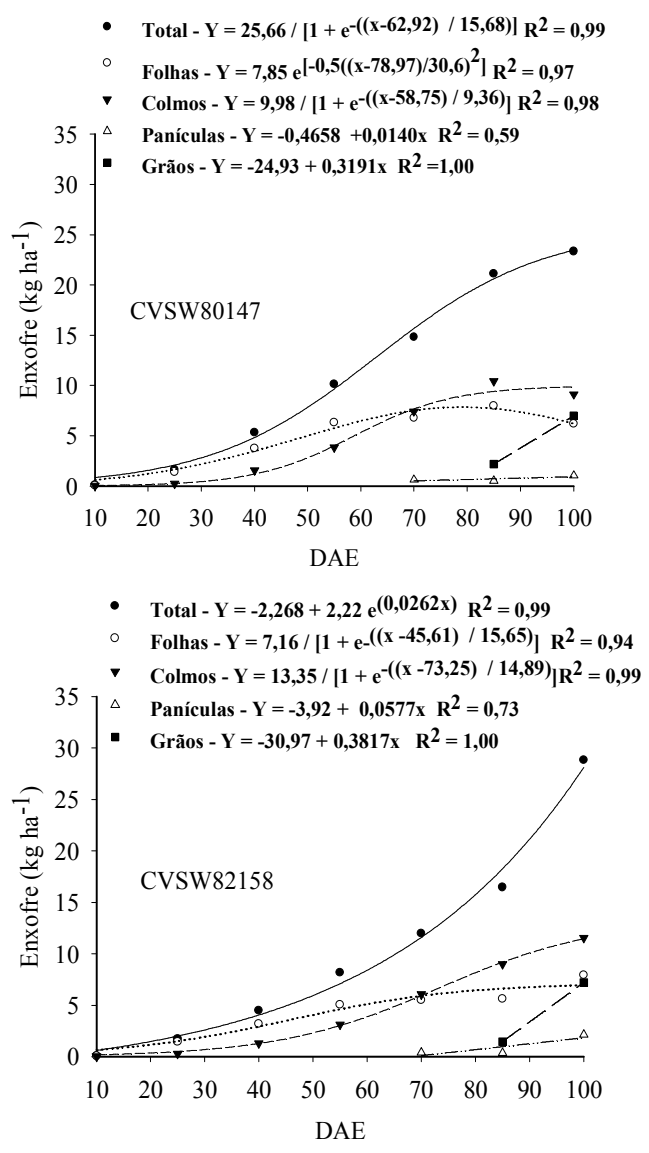

Agradecimentos

A Coordenação de Aperfeiçoamento Pessoal de Nível Superior (CAPES).

\section{Referências}

BATAGLIA, O. C.; FURLANI, A. M. C.; TEIXEIRA, J. P. F.; FURLANI, P. R.; GALlO, J. R. Métodos de análise química de plantas. Campinas: IAC, 1983. 48 p. (Boletim técnico, 78).

CAMARGO, O. A.; MONIZ, A. C.; JORGE, J. A.; VALADARES, J. L. M. A. S. Métodos de análise química, mineralógica e física de solos do Instituto Agronômico de Campinas. Campinas: IAC, 2009. 77 p. (Boletim técnico, 106).

EMPRESA BRASILEIRA DE PESQUISA AGROPECUÁRIA - EMBRAPA. Sistema brasileiro de classificação de solos. 2. ed. Rio de Janeiro: Centro Nacional de Pesquisa de Solos, 2006. 306 p. 
ERICKSON, J. E.; HELSEL, Z. R.; WOODARD, K. R.; VENDRAMINI, J.M.B.; WANG, Y.; SOLLENBERGER, L. E.; GILBERT, R. A. Planting date affects biomass and brix of sweet sorghum grown for biofuel across Florida. Agronomy Journal, Madison, v. 103, n. 6, p. 1827-1833, 2011.

ESPINDULA, M. C.; ROCHA, V. S.; SOUZA, M. A.; CAMPANHARO, M.; PAULA, G. S. Rates of urea with or without urease inhibitor for topdressing wheat. Chilean Journal of Agricultural Research, Chillian, v. 73, n. 2, p. 160-167, 2013.

FRANCO, A. A. N. Marcha de absorção e acúmulo de nutrientes na cultura do sorgo. 2011. Dissertação (Mestrado em Produção Vegetal) - Universidade Estadual de Montes Claros, Janaúba.

HAN, L. P.; STEINBERGER Y.; ZHAO, Y. L.; XIE, G. H. Accumulation and partitioning of nitrogen, phosphorus and potassium in different varieties of sweet sorghum. Field Crops Research, Amsterdam, v. 120, n. 2, p. 230240, 2011.

KLINK, U. P. Melhoramento genético do sorgo para a produção de etanol. Simpósio de Agroenergia-Embrapa Clima Temperado. Pelotas: Embrapa, 2010. Disponível em: $\quad<$ http://www.cpact.embrapa.br/eventos/2010/ simposio_agroenergia/palestras.php>. Acesso em: 16 maio $201 \overline{2}$.

MINISTÉRIO DA AGRICULTURA PECUÁRIA E ABASTECIMENTO - MAPA. Plano nacional de agroenergia 2006-2011. 2. ed. rev. Brasília: Embrapa Informação Tecnológica, 2006. 110 p.

MONTEIRO, J. S. T.; HAVRLAND, B.; INANOVA, T. Sweet sorghum (Sorghum bicolor (L.) Moench) bioenergy value - importance for Portugal. Agricultura Tropica et Subtropica, Suchdol, v. 45, n. 1, p. 12-19, 2012.

OLIVEIRA, E. C. A. de; FREIRE, F. J.; OLIVEIRA, R. I. de; OLIVEIRA, A. C. de; FREIRE, M. B. G. S. Acúmulo e alocação de nutrientes em cana-de-açúcar. Revista Ciência Agronômica, Fortaleza, v. 42, n. 3, p. 579-588, 2011.

PARRELLA, A. da C.; MENEGUCI, J. L. P.; RIBEIRO, A.; SILVA, A. R.; PARELLA, N. N. D.; RODRIGUES, J. A. dos S.; TARDIN, F. D.; SCHAFFERT, R. E. Desempenho de cultivares de sorgo sacarino em diferentes ambientes visando a produção de etanol. In: CONGRESSO NACIONAL DE MILHO E SORGO, 28., 2010, Goiânia. Anais... Goiânia: Associação Brasileira de Milho e Sorgo, 2010.

RAIJ, B. van; ANDRADE, J. C.; CANTARELLA, H.; QUAGGIO, J. A. (Ed.). Análise química para avaliação da fertilidade de solos tropicais. Campinas: IAC, 2001. $285 \mathrm{p}$.
ROONEY, W. L.; BLUMENTHAL, J.; BEAN, B.; MULLET, J. E. Designing sorghum as a dedicated bioenergy feedstock. Biofuels, Bioproducts and Biorefining, Nova Jersey, v. 1, n. 2, p. 147-157, 2007.

ROSOLEM, C. A.; MALAVOLTA, E. Acumulação de matéria seca e macronutrientes pelo sorgo sacarino. Anais Escola Superior de Agricultura Luiz de Queiroz, Piracicaba, v. 38, n. 1, p. 223-241, 1981 b.

Exigências nutricionais do sorgo sacarino. Anais Escola Superior de Agricultura Luiz de Queiroz, Piracicaba, v. 38, n. 1, p. 257-268, 1981a.

SINGH, M. P.; ERICKSON, J. E.; SOLLENBERGER, L. E.; WOODARD, K. R.; VENDRAMINI, J. M. B.; FEDENRO, J. R. Mineral composition and biomass partitioning of sweet sorghum grown for bioenergy in the southeastern USA. Biomass and Bioenergy, Oxford, v. 47, n. 1, p. 1-8, 2012.

UNIÃO DA INDÚSTRIA DA CANA-DE-AÇÚCAR - UNICA. Os desafios do setor sucroenergético e o "movimento + etanol". São Paulo: UNICA, 2012. Disponível em: <http://www.fiesp.com. $\mathrm{br} / \mathrm{irs} /$ agronegocio/pdf/transparencias_reuniao_ cosag_06_02_12_-_marcos_jank_-_20120206_cosag_ jank-unica.pdf $>$. Acesso em: 10 maio 2012.

VENEGAS, J. G.; HARRIS, R. S.; SIMON, B. A. A comprehensive equation for the pulmonary pressurevolume curve. Journal of applied Physiology, Bethesda, v. 84 , n. 1 , p. $389-395,1998$.

VENTURI, P.; VENTURI, G. Analysis of energy comparison for crops in European agricultural systems. Biomass and Bioenergy, Oxford, v. 25, n. 3, p. 235-255, sep. 2003.

VON PINHO, R. G.; BORGES, I. D.; PEREIRA, J. L. de A. R.; REIS, M. C. dos. Marcha de absorção de macronutrientes e acúmulo de matéria seca em milho. Revista Brasileira de Milho e Sorgo, Sete Lagoas, v. 8, n. 2, p. 157-173, 2009.

WORTMANN, C. S.; LISKA, A.; FERGUSON, R. B.; LYON, D. J.; KLEIN, R. N. Dryland performance of sweet sorghum and grain crops for biofuel in Nebraska. Agronomy Journal, Madison, v. 102, n. 1, p. 319-326, 2010.

WU, X. R.; STAGGENBORG, S.; PROPHETER, J. L.; ROONEY, W. L.; YU, J. M.; WANG, H. Features of sweet sorghum juice and their performance in ethanol fermentation. Industrial Crops and Products, Amsterdam, v. 31, n. 1, p. 164-170, 2010.

ZHAO, Y. L.; DOLAT, A.; STEINBERGER, Y.; WANG, X.; OSMAN, A.; XIE, G. H. Biomass yield and changes in chemical composition of sweet sorghum cultivars grown for biofuel. Field Crops Research, Amsterdam, v. 111, n. 1, p. 55-64, 2009. 